\title{
ROBOTIC ACTIVITIES THAT ENGAGE YEAR 6 STUDENTS INTO STEM - VISUAL DESCRIPTIONS OF BEHAVIOUR
}

\author{
Vladimir Estivill-Castro \\ Griffith University (AUSTRALIA)
}

\begin{abstract}
The fundamental role of Science, Technology, Engineering and Mathematics (STEM) skills among the workforce seems to be the source of concern for several modern countries, including Australia, at the National and the State level. However, it is acknowledged that the Australian public has little value on STEM and education in general. and on teacher Nevertheless, we have engaged in a program to bring students on an excursion to University and have a complete day (two sessions of $2.5 \mathrm{hrs}$.) of educational experiences around STEM. We will report in now three years of running these educational activities around robotics. Autonomous robots are the consummation of advances in all disciplines related to STEM. Today autonomous vehicles and the Internet of Things are already radically changing our society faster than the smartphones did just a few years back. Thus, it is important to evaluate how young minds perceive their potential involvement in the fields that lead to careers choices. We expect to motivate non-STEM education to incorporate an understanding of STEM to shape other elements of our society constructively. For example, what is to be expected of responsibilities and liabilities as machines become more autonomous, distributed and self-evolving?

We show that educational activities with robots (in particular software development / programming) are very popular. However, even among the different tasks involving robots, those that lead to personal participation where the job involves human-robot interaction, and physical challenge are even more popular. Thus, activities such as competing against other robots via telepresence, or constructing a small presentation involving robots and humans, receive significantly more rewarding feedback from participants. Young student demonstrates more on interest and engagement in those activities.
\end{abstract}

Keywords: STEM Education Experiences, Experiences in Primary and Secondary education, University/Industry/Government partnership.

\section{INTRODUCTION}

The fundamental role of Science, Technology, Engineering and Mathematics (STEM) skills among the workforce seems to be the source of concern for several modern countries, including Australia, at the National and the State level. However, it is acknowledged that the Australian public has little value on STEM and education in general and on teacher input, STEM teachers, and the promotion of STEM in particular $[15,16,17,18,19]$. Bringing some awareness regarding STEM when most awards during assembly ceremonies are for achievement in sports, followed by milestones in literacy and numeracy (fundamental reading/writing and elementary mathematics) is indeed a challenge.

Therefore, several initiatives have emerged to promote, even from year 6 (the last year of primary school). We have engaged in a program to bring students on an excursion to University and have a complete day (two sessions of $2.5 \mathrm{hrs}$ ) of educational experiences around STEM. We report in now three years of running these educational activities around robotics. Autonomous robots are the consummation of advances in all disciplines related to STEM. There is not only the artificial intelligence and integration of smart systems. Robots represent the embodiment of a computer, the information age, and drones and humanoids are merging artificial agents bringing them to all sorts of environments where people live. Today autonomous vehicles and the Internet of Things are already radically changing our society faster than the smartphones did just a few years back. Thus, it is important to evaluate how young minds perceive their potential involvement in the fields that lead to careers choices. More importantly, address some of the concerns regarding non-STEM; in particular, the number of jobs that demand some level of technological competencies is increasing, and they will also require the ability to work hand in hand with STEM professionals. Thus, there will be an increase of STEM modules in non-STEM courses. We expect to motivate non-STEM education to incorporate an understanding of STEM to shape other elements of our society constructively. For example, what is to be expected of responsibilities and liabilities as machines become more autonomous, distributed and self-evolving? 
We show that educational activities with robots (in particular software development / programming) are very popular. However, even among the different tasks involving robots, those that lead to personal participation where the job involves human-robot interaction, and physical challenge are even more popular. Thus, activities such as competing against other robots via telepresence, or constructing a small presentation involving robots and humans, receive significantly more rewarding feedback from participants. Young student demonstrates more on interest and engagement in those activities.

\section{STEM FOCUS EDUCATION}

STEM knowledge and skills are today considered critical to the management and success of modern society as the industrialised economies depend more and more on research and development projects and maintaining their competitiveness. Professionals and researchers in STEM areas are fundamental to regularly creating and sustaining knowledge-based industries in sectors such as information and communications technology (ICT), bio-informatics, biotechnology and revolutionise further the automation and sophistication of advanced manufacturing. STEM capability provides smart products and enables a competitive edge to traditional industrial sectors as agriculture, mining, and healthcare. Since Australia's fourth largest export industry is education, STEM has been identified as also critical to the education sector. Individuals and societies with values provided by education in STEM result in a diversity of effects that enable cultural and social change as well as a generic mindset and quantitative skills that potentiate the exploration and exploitation of novel opportunities. STEM results in a range of capabilities, from communication skills to deep knowledge of a subject matter, and including critical thinking problem solving, innovation and creativity. These lead to employment and well-being as the workforce is active and participant of wealth generation [15].

Even before the Education Council of Australia made public its strategy and plan for STEM education [7] we started a series of activities in collaboration with junior and senior high-school teacher to engage young students in an effort to steer their interest into STEM subjects. The national strategy suggests two main goals [7]:

1. "Ensure all students finish school with strong foundational knowledge in STEM and related skills."

2. "Ensure that students are inspired to take on more challenging STEM subjects."

And in particular, amongst its five areas for national action, it lists "Increasing teacher capacity and STEM teaching quality". This area of national action lists "STEM professional learning exchange, in partnership with universities and industry" as one of its national collaborative actions.

Our development of STEM activities with robotics aims at contributing to Goal 1 above but also to this particular action. Our activities are part of the STEM 6 program; that is there are for students in Year 6. Year 6 is usually the sixth year of compulsory education. Most children in Year Six are aged between eleven and twelve.

\section{ACTIVITIES}

We developed the activities with the aim of increasing the capacity of students to appreciate the link between computer programming and the specification of behaviour.

The national plan expresses the need to:

"share best practice and identify areas to help boost teacher confidence and capacity in the primary and secondary years, for example in STEM subject content, data analysis and programming."

There is a belief that teaching computer programming (coding) at an early stage enables students to engage STEM and at the very least support STEM delivery. However, there is evidence that the benefits of teaching computer programming are in fact dependent on many diverse factors [6]. Many of these factors are interrelated in complex ways. Nevertheless, there are many initiatives $[1,20]$ by which ICTs or Computer Science knowledge is presented and made accessible to students in highschool.

However, the Australian government, in its Industry Innovation and Competitiveness Agenda introduced coding across the Australian curriculum. The report by Falkner and Vivian [11] found that "while programming is the focus for many of the resources made available, guidelines for how to assess programming, including both assessment of functional correctness and assessment of nonfunctional properties such as design quality, clarity and conciseness, are rarely found." 
But the same report indicated there is "growing prevalence and availability of physical technology designed for the classroom (e.g. Arduino, MaKey MaKey, robotics) opens opportunities for highly interactive learning activities within both Digital Technologies and Design and Technologies and opportunities for integration between these two subject areas."

The focus of our activities is the visual description of behaviour for robots and embedded systems without the need for too much detail on the syntax of computer programming languages and tools. Therefore, we have chosen to present robotic behaviour using logic-labelled finite state machines [8].

Logic-labeled finite state machines LLFSMs are similar to the many paradigms of behaviour modelling presented by finite-state machines. However, in stark contrast to the prevalent event-driven model seen in UML's state diagrams, state-charts by STATEMATE, LLFSMs label transitions by Boolean expressions. We have found that this perhaps simple difference results in a fundamental change of semantics that in fact has many beneficial repercussions in software development, systems modeling, validation, verification and model checking $[9,10]$. Simply put, in an LLFSM the control of execution is always within the sphere of control of the LLFSM itself. In the case of the event-driven semantics, the LLFSM is presumed paused, or sleeping and waiting for an event to happen, at which time, if the current state has a transition labelled with the event, such transition fires and the current state becomes the target state of the transition.

This description of event-driven execution sounds simple, but very quickly a series of semantic issues arise, what if two events arrive at the same time? What if two events come in close proximity? More challenging aspects occur if machines can execute concurrently other machines or invoke submachines that execute concurrently.

In LLFSMs the executing machine evaluates all transitions emanating from its current state in sequence. That is, each transition has a predefined turn where it is evaluated. When the Boolean expression evaluates to true, such current transition is enacted, and the state migration happens. States have OnEntry, OnExit and Internal sections of activities. Only when a transition across different states happens is that the OnEntry and OnExit sections execute. First, the OnExit part of the current source state, and then the onEntry of the target state. The Internal section is executed exactly when all transitions in the sequence evaluate to false. After the activities in the Internal section complete, the execution loops back to the sequential evaluation of the transitions leaving the state.

Figure 1 shows the behaviour that we use to introduce the notion of logic-labeled finite-state machines and we demonstrate with such behaviour being performed by a Nao robot.

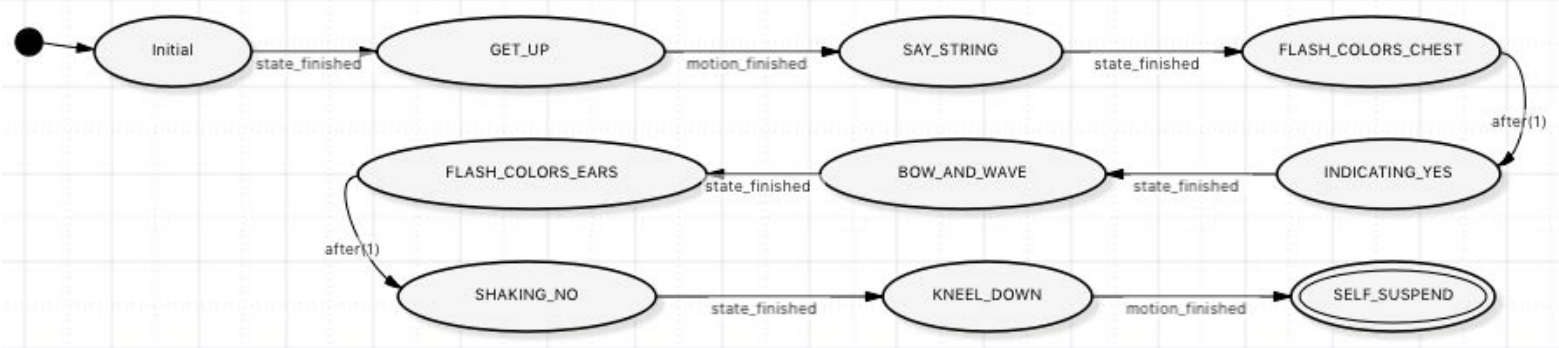

Figure 1 LLFSM that Year 6 students use to start describing behaviours and that is the base for them to build their own behaviours.

The behaviour in Figure 1 is a simple sequence of actions; from the Initial state, the robot stands up from its initial position and says a greeting. Then, its eyes flash different colours, before moving its head up and down indicating yes. The robot kneels, waves and stands up again. Then the ears flash before it moves its head left and right signalling a negation, and finally, it kneels down. The transitions in the behaviour have names like motion finished, and they become true when a motion is completed, while the variable state finished is true when all sub-behaviours are finished. A transition using after $(x)$ is true only after $x$ seconds have passed. The point is that this visualisation of the behaviour is very accessible to Year 6 students (it is significantly similar to the RoboLob that Lego-RCX which was based on LabVIEW). MiCASE is used to explain to the young students the behaviour as it executes on the robot as well. Figure 2 shows that we also explain some aspects of the capability of the visual editor for LLFSMs. In particular, Figure 1 shows each state collapsed, and thus the sections of the states are hidden. 


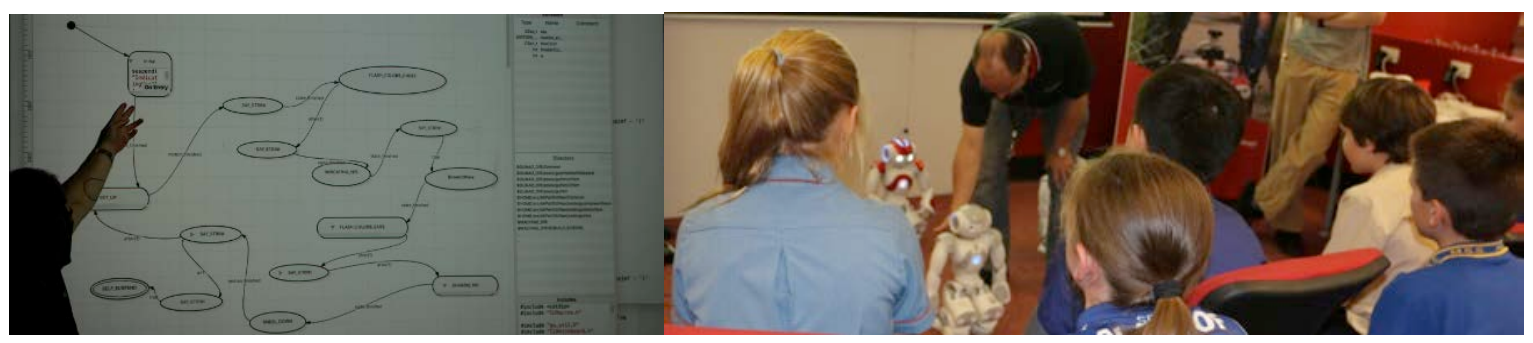

Figure 2 Explaining the LLFSM in Figure 1 and illustrating how the tool MiCASE enables modification of the behaviour.

However, the visualisation for logic-labelled finite-state machines produced here is MiCASE and also used by the Year 6 students to modify, expand and re-invent behaviours on the Nao. Figure 3 shows the tools and environment the students use in the activity; it consists of a Nao robot and the LLFSM editor MiCASE.

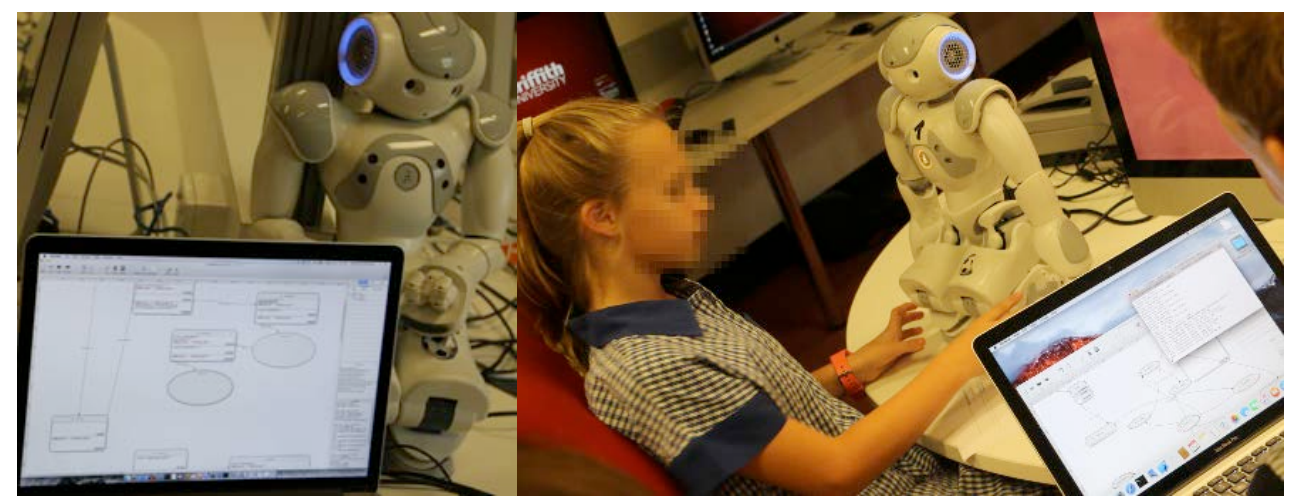

Figure 3 Tools and environment the students use in the activity, it consist of a Nao robot and the LLFSM editor MiCASE.

Figure 4 shows Year 6 participants programming the Nao robot in teams of 4 to 5 students. The development of their behaviours may require several iterations and testing. Robotics provide an embodiment of the behaviour that has analogies to the claims of introducing programming to children with Logo [2] or the visualisations produced by the environment Alice [3]. Robotics is not virtual, but real. That is, the behaviour is performed in the real world, with physical limitations. Note that for many years, it has been pointed out that computer programming per se does not improve problem-solving skills [4] and that some instruction in problem solving is required.

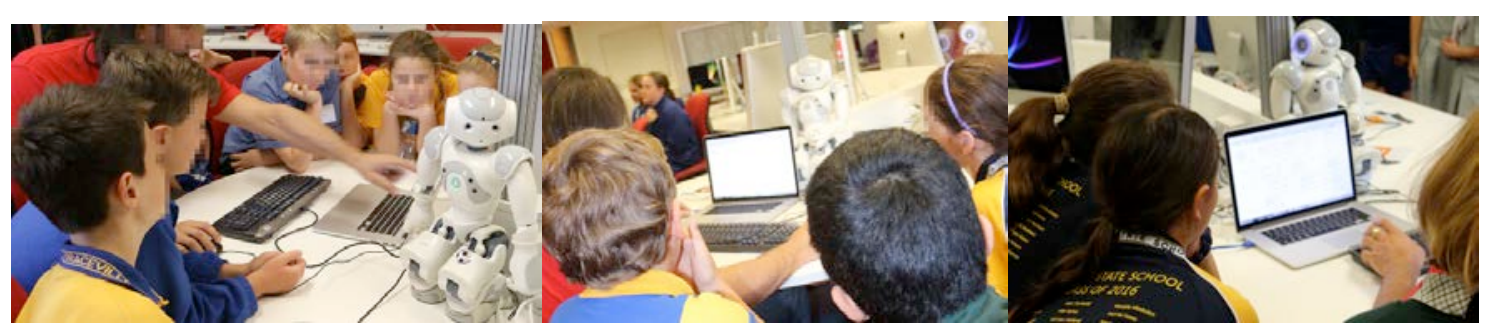

Figure 4 Students collaborating and composing new LLFSM and thus building new behaviours.

Figure 5 shows some of the participant students' interaction with the Nao robot while validating the behaviour on a test run. 


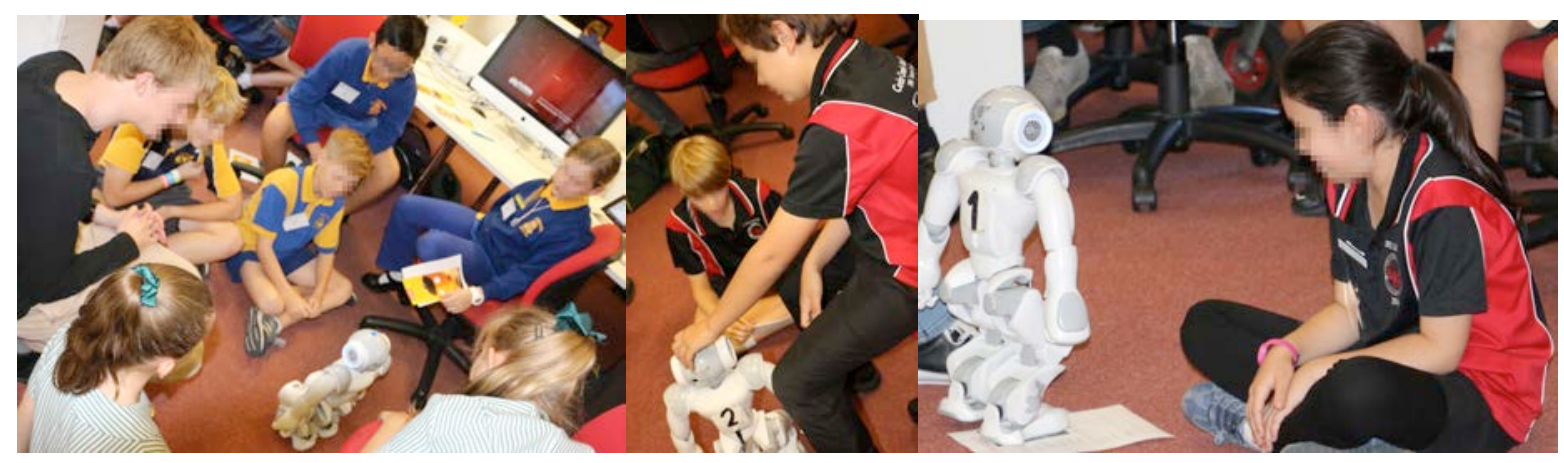

Figure 5 Students collaborating and composing new LLFSM and thus building new behaviours.

The students also participate in an activity that demonstrates feedback-loop control. Feedback loop control is also illustrated with logic-labeled finite state machines, it introduces the concept of a loop in the model of the behaviour that executes extremely fast. Its physical demonstration is with a flying quadcopter, as the quadcopter is in equilibrium because the feedback loop control accelerates and deaccelerates each of the four propels to keep it floating in the air to steer in into directions of control. Students attempting take-off and landing with an iPad control that uses tilting sensors to indicate direction to the quadcopter. We also rely the images from a camera on board of the flying robot to the controlling iPad to create a telepresence platform. Figure 6 shows students engaging in the remote control activity.

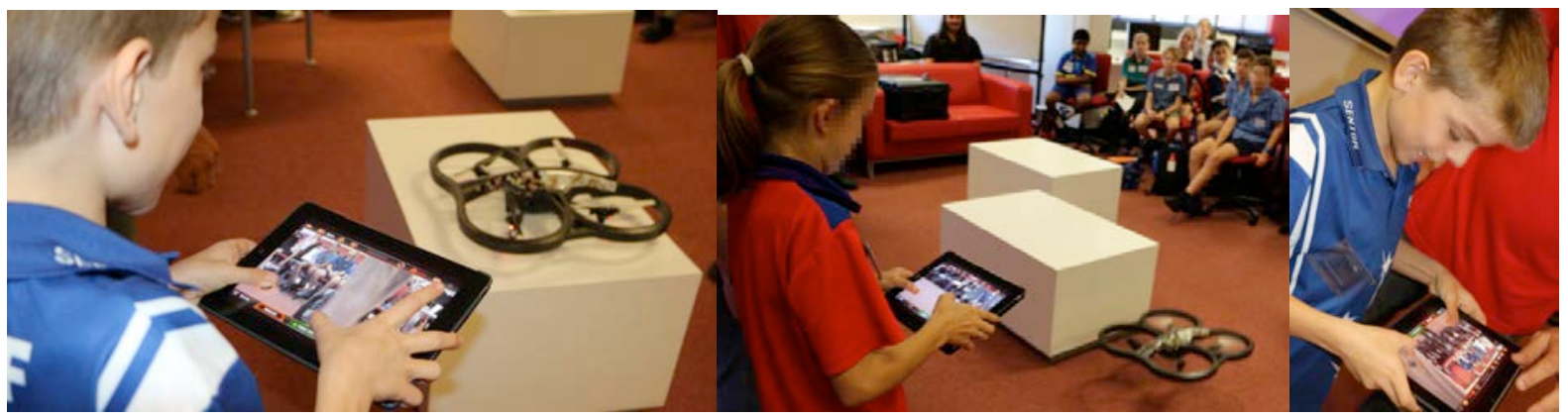

Figure 6 Students using and iPad to remote control a flying quadcopter. The robot has a camera on board whose input is displayed on the iPad's screen.

We also enable students to participate in a contest to chase and kick the ball while controlling the robot using a telepresence tool. This activity works as a discrepant event [14] to cause conceptual change. Students rapidly suggest they will perform better than the autonomous robots in chasing and kicking the ball, particularly after observing the robot carry out the task. It is certainly slower that a human at all sub-aspects of the task from searching and finding the ball, to walking and following it, and even judging the distance to execute a kick. However, all the challenges of telepresence [12] come to light when the students attempt the same task using telepresence. We believe the activity provides opportunity to create a shared meaning in the most conventional constructivist approach [13].

Figure 7 shows students engaging in the telepresence activity.

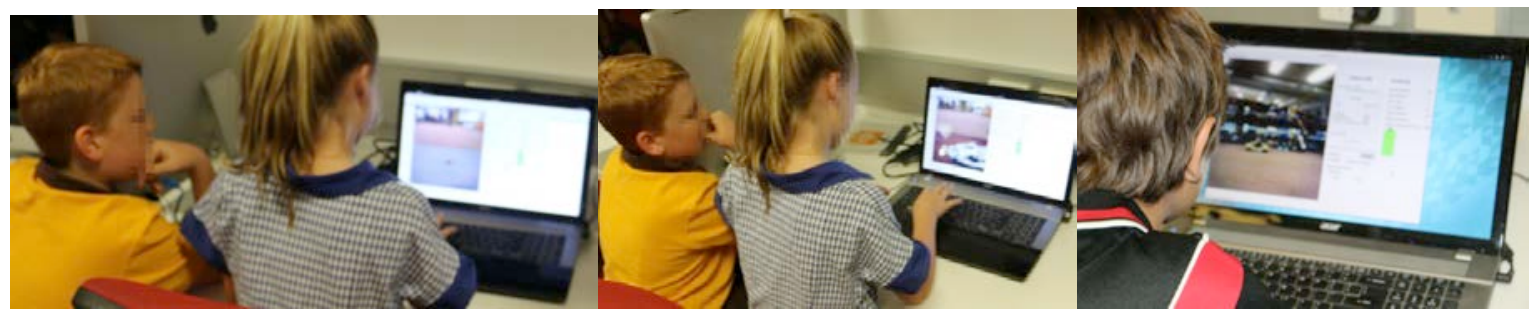

Figure 7 Students controlling Nao robots with a telepresence software and competing against fully autonomous robots in a soccer match. 


\section{EVALUATION}

There is a variety of methodologies under discussion to collect data about the success of STEM teaching activities [3]. We collected feedback from the participants regarding the STEM 6 activities discussed and also in contrast with other activities in STEM and even with other robotics activities. We present the results of this evaluation. The results are over 114 students from 35 schools. The satisfaction survey (refer to Figure 8) shows that the students experience with the activities is extremely positive.

In all satisfaction question the item "Strongly Agree" was chosen by more than $60 \%$ of the participants. If we include "Agree", then at least $90 \%$ of the students had a positive experience reflected by all four questions.

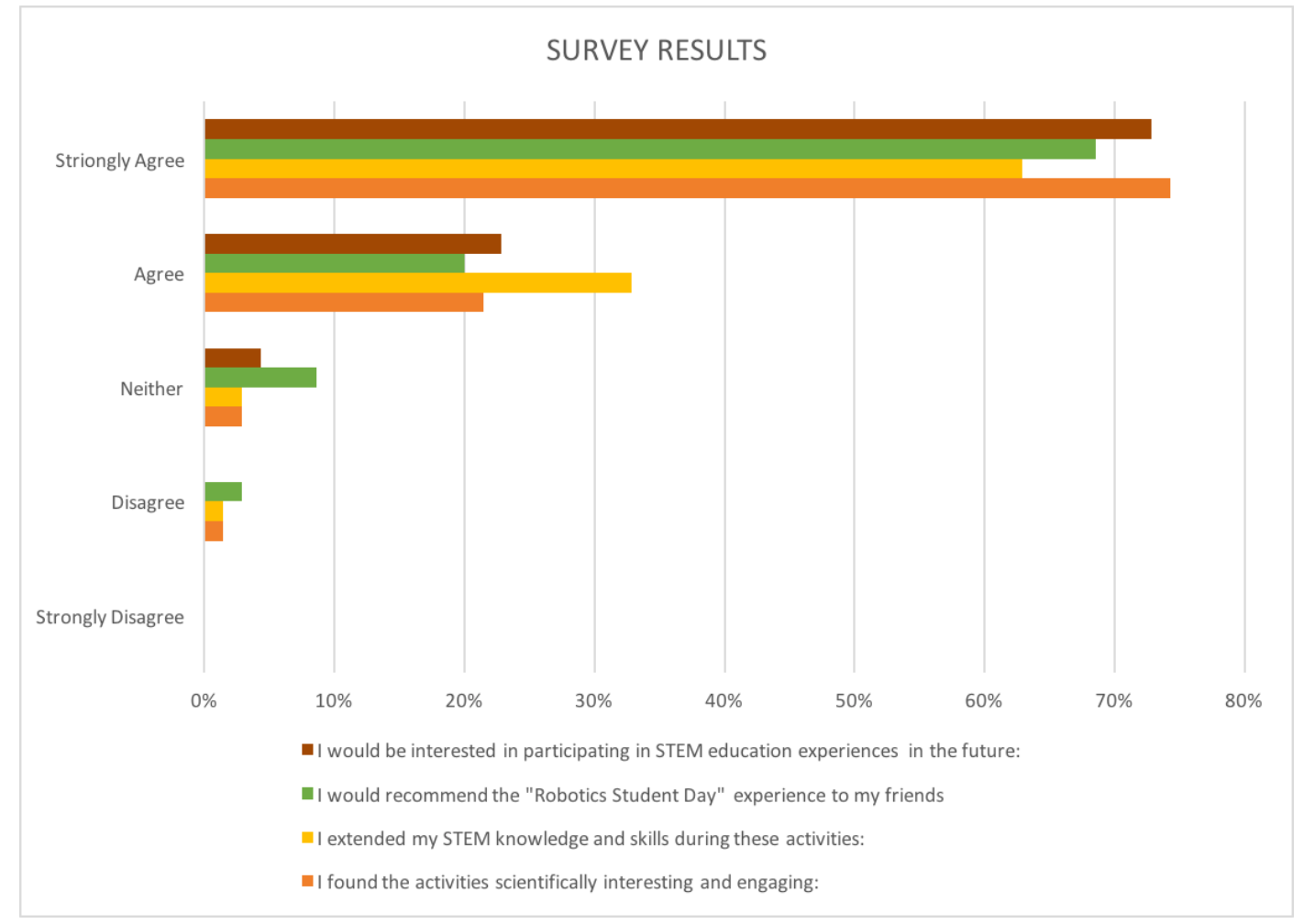

Figure 8 Results of evaluation survey of the experience across four questions.

Figure 9 shows a comparison with other activities on robotics at programming with the same students. In this case, the programming is less visual and more textual.

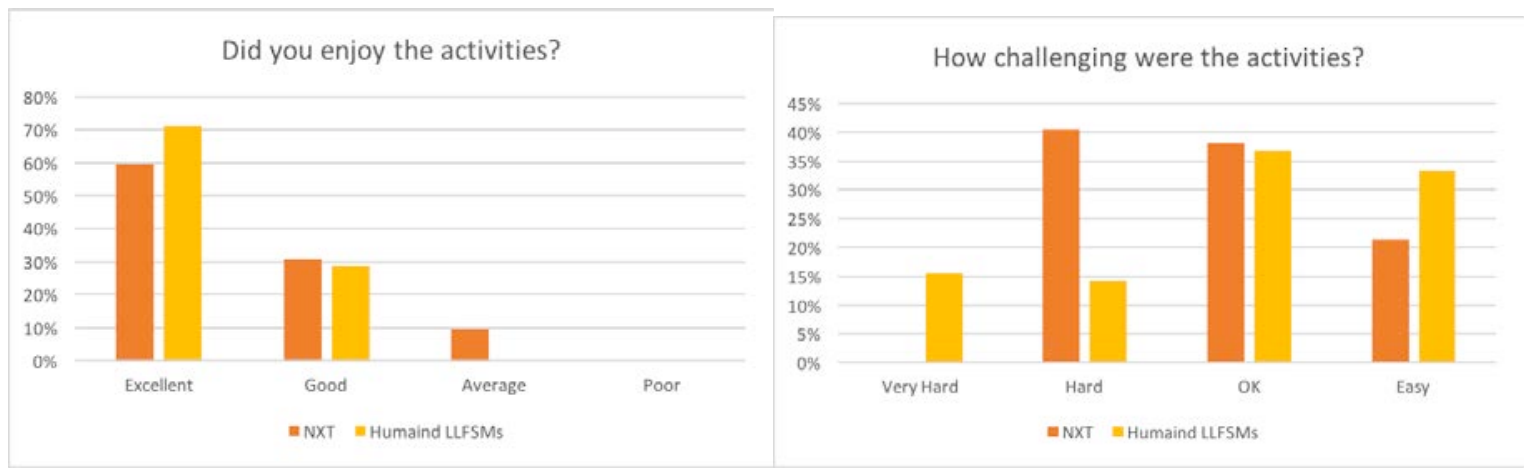

Figure 9 Comparison with other robotics programming activity.

There is an even spread of how challenging are the activities when using LLFSMs over the more textual language. There are many factors that could also had influenced this result. For example, there were more supporting staff when developing behaviours for humanoids under LLFSMs. Nevertheless, 
it is clear that the students not only were presently challenged by the behaviour development with LLFSMs, but also they felt the activity was more enjoyable.

With respect to the type of activity, Figure 10 is the one that seems to be more interesting. Here, the project/tasks consisted of creating a behaviour where humans and the robot could participate. Some created a play; others created a choreographic dance. A very fascinating one was a version of "Simple Simon Says".

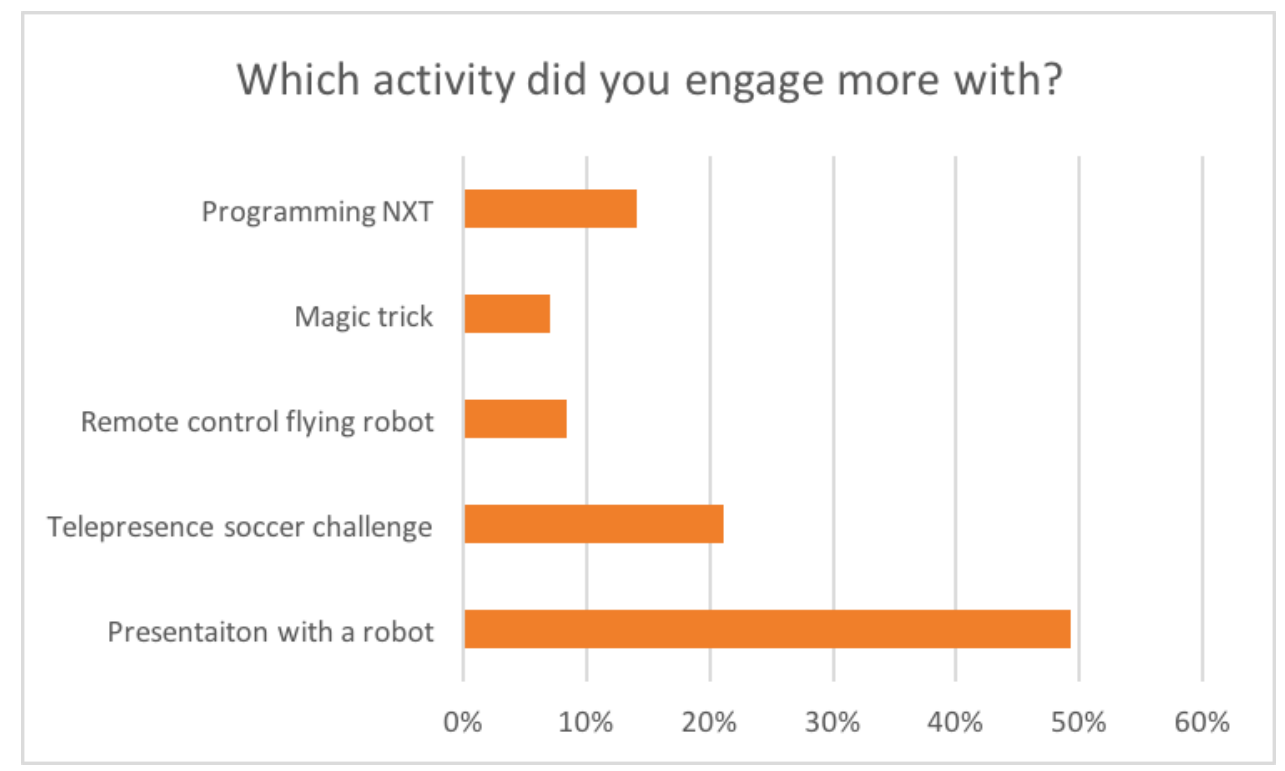

Figure 10 Results of evaluation survey of the preferred activity with the humanoid robot and LLFSM behaviour development.

We see that the activity in which humans will also participate with the humanoid robot in the performance of the behaviour was preferred much more than the others.

\section{CONCLUSIONS}

The visits to University and the robotics activities where students can

1 rapidly introduced to robot behaviour development by visual tools for the composition of behaviours, and

2 students can participate in project or tasks where they are also participants

are very engaging for Year 6 participants. They certainly find that they have been introduced to an area of knowledge that they would like to know more. Even if they are not developing programs or coding, this opens their mindset to a series of possibilities of the impact of automation in society. The interest in STEM education should not only be about the readiness of building a skilful population of professionals. It also involves an understanding of the purpose of technology for the benefits of society, raising living standards and appreciating what is human. The activities invite the participants to reflect on the possible beneficial uses of humanoid robots. Unfortunately, we have not been able to collect enough data, but we leave for future work to analyse the attitudes of participants to these activities on the impact of automation and society.

\section{ACKNOWLEDGEMENTS}

I am deeply thankful to my colleague Dr. Andrew Rock and also to several supporting students: Dimitri Joukoff, Carl Lusty, Eugene Gilmore, Mick Hawkins, Brenainn Moushall, Callum McColl. 


\section{REFERENCES}

[1] T. Bell, J. Alexander, I. Freeman, and M. Grimley. Computer science unplugged: school students doing real computing without computers. New Zealand Journal of Applied Computing and Information Technology, 13(1):20-29, 2009.

[2] Douglas $\mathrm{H}$. Clements. Longitudinal study of the effects of logo programming on cognitive abilities and achievement. Journal of Educational Computing Research, 3(1):73-94, 1987.

[3] S. Cooper. Programming with Alice. J. Comput. Sci. Coll., 23(4):162-162, April 2008.

[4] D. W. Dalton and D. A. Goodrum. The effects of computer programming on problem-solving skills and attitudes. Journal of Educational Computing Research, 7(4):483-506, 1991.

[5] M. H. Dancy, M.T. Hora, J.J. Ferrare, E. Iverson, L. R Lattuca, and J. Turns. Describing \& measuring undergraduate STEM teaching practices - a report from a National Meeting on the Measurement of Undergraduate Science, Technology, Engineering, and Mathematics (STEM) teaching. American Association for the Advancement of Science (AAAS), December $17^{\text {th }}-19$ th 2012.

[6] C. Duncan, T. Bell, and S. Tanimoto. Should your 8-year-old learn coding? In Proceedings of the 9th Workshop in Primary and Secondary Computing Education, WiPSCE '14, pages 60-69, New York, NY, USA, 2014. ACM.

[7] Education Council. National STEM school education strategy, 2016 â €“2026 —a comprehensive plan for science, technology, engineering and mathematics education in Australia. www.educationcouncil.edu.au, December 2015.

[8] V. Estivill-Castro and R. Hexel. Arrangements of finite-state machines semantics, simulation, and model checking. In S. Hammoudi, L. Ferreira Pires, J. Filipe, and R. César das Neves, editors, International Conference on Model-Driven Engineering and Software Development MODELSWARD, pages 182-189, Barcelona, Spain, 19-21 February 2013. SCITEPRESS Science and Technology Publications.

[9] V. Estivill-Castro and R. Hexel. Correctness by construction with logic-labeled finite-state machines - comparison with Event-B. In L. Zhu and J. Steel, editors, Proc. 23rd Australasian Software Engineering Conference (ASWEC), pages 38-47, Milsons Point, Sydney, NSW, Australia, April 7th-10th 2014. IEEE Computer Society Conference Publishing Services (CPS).

[10] V. Estivill-Castro and R. Hexel. Simple, not simplistic - the middleware of behaviour models. In ENASE 10 International Conference on Evaluation of Novel Approaches to Software Engineering, Barcelona, Spain, April 2015. INSTCC.

[11] K. Falkner and R. Vivian. Coding across the curriculum — resource review (final report). School of Computer Science, The University of Adelaide, 2015.

[12] A. Kristoffersson, S. Coradeschi, and A. Loutfi. A review of mobile robotic telepresence. Adv. in Hum.-Comp. Int., 2013:3-17, January 2013.

[13] J. J. Mintzes and J. H. Wandersee. Chapter 2: Reform and innovation in science teaching: a human constructivist view. In J. J. Mintzes, J. H. Wandersee, and J. Novak, editors, Teaching science for understanding: a human constructivist view, pages 29-58, San Diego, CA, 1998. Academic Press.

[14] T. O'Brien. Brain-powered science: teaching and learning with discrepant events. National Science Teachers Association NSTA Press, Arlington, VA, 2010.

[15] Office of the Chief Scientist. Australia's STEM workforce. Australian Government, Canberra, march 2014.

[16] Office of the Chief Scientist. Science, technology, engineering and mathematics: Australia's future. Australian Government, Canberra, 2014.

[17] Office of the Queensland Chief Scientist. Roadmap to STEM education in Queensland. Queensland Government, November 6th 2013. 
[18] F. Quinn and T. Lyons. Choosing science: understanding the declines in senior high school science enrolments. Technical report, University of New England, SiMERR National Research Centre, Armidale, NSW, 2010.

[19] L. J. Rennie, D. Goodrum, and M. Hackling. Science teaching and learning in Australian schools: Results of a national study. Research in Science Education, 31(4):455-498, 2001.

[20] J. A. Rursch, A. Luse, and D. Jacobson. It-adventures: A program to spark it interest in high school students using inquiry-based learning with cyber defense, game design, and robotics. IEEE Transactions on Education, 53(1):71-79, Feb 2010. 